\title{
Ab-initio calculations of the first ionization potential of silatranes and the electronic structure of their radical cations
}

\author{
Vera V. Belyaeva, Yulii L. Frolov, and Mikhail G. Voronkov* \\ A. E. Favorsky Irkutsk Institute of Chemistry, Siberian Branch RAS, \\ 1, Favorsky Street, Irkutsk, 664033, Russia Federation \\ E-mail: voronkov@irioch.irk.ru
}

Dedicated to Professor Vladimir Minkin on the occasion of his $70^{\text {th }}$ birthday

(received 01 Dec 04; accepted 25 Feb 05; published on the web 11 Mar 05)

\begin{abstract}
Ab-initio quantum chemical calculations of the first ionization potentials in the photoelectron spectra of 1-substituted silatranes, $\mathrm{XSi}\left(\mathrm{OCH}_{2} \mathrm{CH}_{2}\right)_{3} \mathrm{~N}\left(\mathrm{X}=\mathrm{H}, \mathrm{CH}_{3}, \mathrm{ClCH}_{2}, \mathrm{~F}\right)$ and the electronic structure of their radical cations have been carried out. The difference between full energy of the molecule and the corresponding radical cation was determined by the use of the density functional theory and the MP2 approximation.
\end{abstract}

Keywords: Silatrane, ionization potential, quantum chemical calculations, radical cation

\section{Introduction}

The second half of the last century was marked by a rapid development of the chemistry of silatranes, triethanolamine intracomplex organosilicon derivatives, containing the pentacoordinate silicon atom and corresponding to a general formula $\mathrm{XSi}\left(\mathrm{OCH}_{2} \mathrm{CH}_{2}\right)_{3} \mathrm{~N}$.

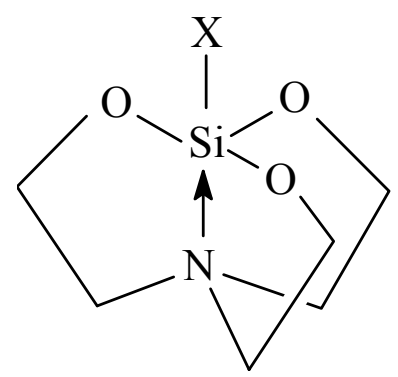

Figure 1. 1-Substituted silatrane structure $\left(\mathrm{X}=\mathrm{H}, \mathrm{CH}_{3}, \mathrm{CH}_{2} \mathrm{Cl}, \mathrm{F}\right)$. 
The immense interest among researches in these compounds was aroused by their unusual polyhedral structure, the presence of a hypervalent $\mathrm{X}-\mathrm{Si}-\mathrm{N}$ fragment, their specific physical properties, often unique reactivity, and a broad spectrum of biological activity. ${ }^{1-3}$

The electronic structure of silatranes was studied by almost all physical method available. However, the number of publications devoted to the photo-electron spectra (PES) and ionization potentials (IPv) of these compounds is rather scarce, ${ }^{4-8}$ and the interpretation of the data led to erratic conclusions in many cases. ${ }^{8}$ On the other hand, PES of silatranes are essential for explaining the origin of the three-centered four-electron $\mathrm{X}-\mathrm{Si}-\mathrm{N}$ bond. Our goal was to calculate, using ab-initio quantum-chemical methods, the first vertical ionization potentials as the difference between total energies of the molecule and the corresponding radical cation (without changing the optimized molecular core geometry) in the series of 1-substituted silatranes $\mathrm{XSi}\left(\mathrm{OCH}_{2} \mathrm{CH}_{2}\right)_{3} \mathrm{~N}\left(\mathrm{X}=\mathrm{H}, \mathrm{CH}_{3}, \mathrm{ClCH}_{2}, \mathrm{~F}\right)$.

\section{Calculations}

Calculations were carried out using the density functional theory (DFT) and the MP2 method of perturbation theory with an extensive set of basis functions and total optimization of the geometry. Calculations of the vertical ionization potentials (IPv) used the optimized geometry of molecules for radical cations. Adiabatic exitation was investigated also. In this case cation radical geometry was optimized.

Calculations were performed using program package Gaussian $98 \mathrm{~W} .{ }^{9}$

\section{Results and Discussion}

For silatranes with substituents in the silicon atom where $\mathrm{X}=\mathrm{H}(\mathbf{I}), \mathrm{CH}_{3}$ (II), $\mathrm{ClCH}_{2}$ (III) and $\mathrm{F}$ (IV), we used sets of basis functions from relatively broad ones: B (B3LYP/6-311++(3df, p)) and $\mathrm{C}(\mathrm{B} 3 \mathrm{LYP} / 6-311+(3 \mathrm{~d}, \mathrm{p}))$ to those we recognized as optimal: A (B3LYP/6-311(2d). This basis set provide an appropriate relation: quality - calculation time. The results of the calculations are presented in Table 1.

The calculated ionization potentials, based on the B3LYP method, were 0.4-0.7 eV below experimental IPv values of the 'controversial' first potential. The expansion of the basis sets B and $\mathrm{C}$ leads to a closer agreement between theoretical and experimental data; the difference between these values for compounds II and IV is 0.35 and $0.38 \mathrm{eV}$, respectively. Using the MP2 approximation with basis set B gave calculated values near experimental. Particularly the value of calculated $\mathrm{N} \rightarrow \mathrm{Si}$ bond length was changed from $270 \mathrm{pm}$ to $246 \mathrm{pm}$, that is also close to the

experimental one. ${ }^{10}$ So, overall, our results provide convincing evidence that the first band in the PES of 1-substituted silatranes bears no relation to the admixture; it belongs to the silatrane molecules and corresponds, according to its value, to the ionization of the endocyclic nitrogen atom. The IPv value $8-9 \mathrm{eV}$ is consistent with the three-centered four-electron origin of the 
intramolecular coordination in silatranes. Earlier we showed that first ionization potentials of silatranes linearly correlated with the shielding constant of the nitrogen atom in NMR spectra, the length of the coordination bond $\mathrm{Si}-\mathrm{N}$ and the inductive constant of the silicon atom substituent. $^{7}$

Table 1. Calculated full energies and first ionization potentials of silatrane molecules, $\mathrm{XSi}\left(\mathrm{OCH}_{2} \mathrm{CH}_{2}\right)_{3} \mathrm{~N}$

\begin{tabular}{|c|c|c|c|c|c|c|}
\hline X, № & Compound & Method, basis set & Geometry & $\mathrm{E}_{\text {total }}$, a.u. & $\mathrm{IP}_{\mathrm{v}}, \mathrm{eV}$ & $\mathrm{IP}_{\mathrm{V}}, \mathrm{eV} \exp$ \\
\hline \multirow{4}{*}{$\mathrm{H}, \mathbf{I}$} & molecule & B3LYP/6-311G(2d) & optim. & -806.6489557 & 8.46 & \multirow{4}{*}{$\begin{array}{l}10.1 \\
10.4\end{array}$} \\
\hline & radical cation & UB3LYP/6-311G(2d) & molecul.* & -806.3378352 & - & \\
\hline & molecule & MP2/6-311G(2d) & optim. & -805.1054582 & 9.58 & \\
\hline & radical cation & UMP2/6-311G(2d) & molecul. & -804.7535825 & - & \\
\hline \multirow{7}{*}{$\mathrm{CH}_{3}, \mathbf{I I}$} & molecule & $\begin{array}{c}\text { B3LYP/6- } \\
311++G(3 d f, p)\end{array}$ & optim. & -846.0481817 & 8.15 & \multirow{7}{*}{$\begin{array}{c}8.5 \\
9.8 \\
10.2\end{array}$} \\
\hline & radical cation & $\begin{array}{c}\text { UB3LYP/6- } \\
311++G(3 d f, p)\end{array}$ & molecul. & -845.7487266 & - & \\
\hline & molecule & B3LYP/6-311G(2d) & optim. & -845.9885272 & 8.05 & \\
\hline & radical cation & UB3LYP/6-311G(2d) & molecul. & -845.6926057 & - & \\
\hline & radical cation & UB3LYP/6-311G(2d) & optim. & -845.7146376 & - & \\
\hline & molecule & MP2/6-311G(2d) & optim. & -844.3324594 & 8.98 & \\
\hline & radical cation & UMP2/6-311G(2d) & molecul. & -844.0026274 & - & \\
\hline \multirow{2}{*}{$\begin{array}{c}\mathrm{CH}_{3}, \\
\mathrm{R}_{\mathrm{N} \rightarrow \mathrm{Si}} \\
=220 \\
\mathrm{~nm}\end{array}$} & molecule & B3LYP/6-311G(2d) & optim. & -845.9812136 & 8.78 & \\
\hline & radical cation & UB3LYP/6-311G(2d) & molecul. & -845.6587115 & - & \\
\hline \multirow{2}{*}{$\begin{array}{c}\mathrm{ClCH}_{2}, \\
\text { III }\end{array}$} & molecule & B3LYP/6-311G(2d) & optim. & $-1305,6084882$ & 8.53 & \multirow{2}{*}{$\begin{array}{c}9.2 \\
10.0 \\
10.3 \\
\end{array}$} \\
\hline & radical cation & UB3LYP/6-311G(2d) & molecul. & -1305.2951414 & - & \\
\hline \multirow{6}{*}{$\mathrm{F}, \mathbf{I V}$} & molecule & B3LYP/6-311+G(3d,p) & optim. & -906.0439093 & 9.32 & \multirow{6}{*}{$\begin{array}{c}9.7 \\
10.0 \\
10.7\end{array}$} \\
\hline & radical cation & UB3LYP/6-311+G(3d,p) & molecul. & -905.7015529 & - & \\
\hline & molecule & B3LYP/6-311G(2d) & optim. & -906.0013936 & 9.01 & \\
\hline & radical cation & UB3LYP/6-311G(2d) & molecul. & -905.6703183 & - & \\
\hline & molecule & MP2/6-311G(2d) & optim. & -904.3253273 & 9.79 & \\
\hline & radical cation & UMP2/6-311G(2d) & molecul. & -903.9653990 & - & \\
\hline
\end{tabular}

* Used optimized molecular geometry.

According to our calculations the adiabatic potential $0.5 \mathrm{eV}$ is below the vertical potential. One conceivable reason for this difference could be the character of the potential function, corresponding to the total energy of the silatrane molecule on the coordination $\mathrm{Si}-\mathrm{N}$ bond length. 
This function was investigated in more detail ${ }^{11-13}$. Energy changes over 230-290 pm range do not exceed $1 \mathrm{kcal} / \mathrm{mol}$. A considerable width of the potential curve that leads to the coordination bond lability is responsible for a larger half-width and a low peak intensity of the first band in the PES of silatranes. Calculations for the methylsilatrane molecule (Table 1) carried out with a fixed N-Si distance of $220 \mathrm{pm}$ gave a IPv value as high as $8.78 \mathrm{eV}$; this is consistent with the main conclusion that the first band of the PE spectrum should belong to the ionization of an endocyclic nitrogen atom participating in the coordination bond.

The localization of the ionized fragment in the silatrane molecule is clearly illustrated by two characteristics of radical cations. Firstly, in the adiabatic ionization process the length of the coordination $\mathrm{Si}-\mathrm{N}$ bond increases sharply (in the case of 1-methylsilatrane - to 313-316 nm), which is indicative of an attenuation of the bond. This is the result of the electron detachment from the bonding orbital of the $\mathrm{Si}-\mathrm{N}$ fragment. Secondly, in the radical cations over $50 \%$ of the spin density amount is localized on the nitrogen atom. For the other atoms, the spin density averages 0.01-0.02 and does not exceed 0.09. The ionization of molecules results in a sharp decrease in the N-Si bond lengths, which indicates not only the origin of the ionized fragment, but points to the possible existence of steric tricyclic structures with such distances between the nitrogen and silicon atoms.

Table 2 shows the atomic charges and their ionization induced redistribution in the compound under consideration (B3LYP method, basis set 6-311G(2d)). It is evident that the positive charge of the radical cations moves to the hydrogen atoms. The negative charge on the nitrogen atom decreases only by $0.23-0.26$ a.u., whereas the positive charge on the silicon atom increases only by 0.03-0.06 a.u.

Table 2. Calculated by B3LYP/6-311G(2d) method charges (q) in molecules of $\mathrm{XSi}\left(\mathrm{OCH}_{2} \mathrm{CH}_{2}\right)_{3} \mathrm{~N}\left[\mathrm{X}=\mathrm{H}(\mathbf{I}), \mathrm{CH}_{3}\right.$ (II) and their radical cations (italics)]

\begin{tabular}{|c|c|c|c|c|c|c|c|c|c|}
\hline \multicolumn{2}{|c|}{$\mathrm{X}=\mathrm{CH}_{3}$} & \multirow{2}{*}{$\begin{array}{c}\mathrm{X}=\mathrm{H} \\
\mathrm{q}(\mathrm{H})\end{array}$} & \multirow{2}{*}{$\mathrm{q}(\mathrm{Si})$} & \multirow{2}{*}{$\mathrm{q}(\mathrm{N})$} & \multirow{2}{*}{$\Sigma q\left(C_{\alpha}\right)$} & \multirow{2}{*}{$\Sigma q\left(C_{\beta}\right)$} & \multirow{2}{*}{$\Sigma \mathrm{q}\left(\mathrm{H}_{\alpha}\right)$} & \multirow{2}{*}{$\Sigma \mathrm{q}\left(\mathrm{H}_{\beta}\right)$} & \multirow{2}{*}{$\Sigma q(O)$} \\
\hline $\mathrm{q}(\mathrm{C})$ & $\Sigma q(H)$ & & & & & & & & \\
\hline-0.937 & 0,673 & & 1.780 & $-0,365$ & -1.005 & -0.462 & 1.317 & 1.263 & -2.268 \\
\hline-0.963 & 0.807 & & 1.811 & -0.136 & -1.152 & -0.540 & 1.791 & 1.602 & -2.220 \\
\hline \multicolumn{10}{|c|}{ Charge difference on the atoms in molecule and radical cation } \\
\hline \multirow[t]{5}{*}{-0.026} & 0.134 & & 0.031 & 0.229 & -0.147 & -0.078 & 0.474 & 0.339 & 0.048 \\
\hline & & -0.051 & 1.469 & -0.393 & -1.002 & -0.420 & 1.338 & 1.275 & -2.217 \\
\hline & & 0.065 & 1.526 & -0.137 & -1.164 & -0.519 & 1.812 & 1.629 & -2.214 \\
\hline & \multicolumn{9}{|c|}{ Charge difference on the atoms in molecule and radical cation } \\
\hline & & 0.116 & 0.057 & 0.256 & -0.162 & -0.099 & 0.474 & 0.354 & 0.003 \\
\hline
\end{tabular}




\section{Conclusions}

Ionization potentials of four 1-substituted silatranes were calculated by ab inititio methods as differences between total energies of the molecules and their radical cations. This confirmed that the PES bands in the region $8-10 \mathrm{eV}$ correspond to the first ionization potentials of these molecules. Spin densities are localized on the nitrogen atom of these radical cations. The electronic charge decrease takes place on the nitrogen atom, the substituent and the hydrogen atoms of the methylene groups.

\section{References}

1. Voronkov, M.G.; Dyakov, V.M.; Kirpichenko, S.V. J. Organomet. Chem. 1982, 233, 1.

2. Tandura, S.N.; Voronkov, M.G.; Alekseev, N.V. Top. Curr. Chem. 1988, 131, 99.

3. Pestunovich, V.A.; Kirpichenko, S.V.; Voronkov, M.G. In The chemistry of organic silicon compounds Rappoport, Z.; Apeloig, Y., Eds; Wiley: New York, 1998.

4. Peel, J.B.; Wang, D.J. J. Chem. Soc., Dalton Trans. 1988, 7, 1963.

5. Cradock, S.; Ebsworth, E.A.; Muire, J.B. J. Chem. Soc., Dalton Trans. 1975, 25.

6. Voronkov, M.G.; Brodskaya, E.I.; Belyaeva, V.V.; Lazareva, N.F. Izv. Akad. Nauk. Ser. Khim. 2001, 725.

7. Belyaeva, V.V.; Voronkov, M.G. Zh. Struct. Khim. 2001, 42, 826.

8. Sidorkin, V.F.; Balakhchi, G.K. Struct. Chem. 1994, 5, 189.

9. Frisch, M.J.; Trucks, G.W.; Schlegel, H.B.; Scuseria, G.E.; Robb, M.A.; Cheeseman, J.R.; Zakrzewski, V.G.; Montgomery, J.A.; Jr., Stratmann, R.E.; Burant, J.C.; Dapprich, S.; Millam, J.M.; Daniels, A.D.; Kudin, K.N.; Strain, M.C.; Farkas, O.; Tomasi, J.; Barone, V.; Coss, M.; Cammi, R.; Mennucci, B.; Pomelli, C.; Adamo, C.; Clifford, S.; Ochterski, J.; Petersson, G.A.; Ayala, P.Y.; Cui, Q.; Morokuma, K.; Malick, D.K.; Rabuck, A.D.; Raghavachari, K.; Foresman, J.B.; Cioslowski, J.; Ortiz, J.V.; Stefanov, B.B.; Liu, G.; Liashenko, A.; Piskorz, P.; Komaromi, I.; Gomperts, R.; Martin, R.L.; Fox, D.J.; Keith, T.; Al-Laham, M.A.; Peng, C.Y.; Nanayakkara, A.; Gonzalez, C.; Challacombe, M.; Gil, P.M.W.; Johnson, B.; Chen, W.; Wong, M.W.; Andres, J.L.; Gonzalez, C.; Head-Gordon, M.; Replogle, E.S.; Pople, J.A. Gaussian 98W, Revision A.6, Gaussian, Inc., Pittsburgh PA, 1998.

10. Shen, Q.; Hilderbrandt, R.L. J. Molec. Struct. 1980, 64, 257

11. Csonka, G.I.; Hencsei, P. J. Comput. Chem. 1994, 15, 385.

12. Schmidt, M.W.; Windus, T.L.; Gordon, M.S. J. Amer. Chem. Soc. 1995, 117, 7480.

13. Boggs, J.E.; Peng, Ch.; Pestunovich, V.A.; Sidorkin, V.F. J. Molec. Struct. (Theochem) 1995, 357, 67. 